\title{
sciendo
}

\section{Reframing business reporting in a Big Data world}

\author{
Adriana DUTESCU \\ Bucharest University of Economic Studies, Bucharest, Romania \\ adriana.dutescu@bsm-mba.ro \\ Irina Bogdana PUGNA \\ Bucharest University of Economic Studies, Bucharest, Romania \\ irina.pugna@cig.ase.ro \\ Georgiana Oana STANILA \\ Bucharest University of Economic Studies, Bucharest, Romania \\ oana.stanila@cig.ase.ro
}

\begin{abstract}
This paper investigates the challenges raised by the "datafication" of the business environment in the area of performance management. Big Data and its powerful analytics are now essential elements of the business landscape, and the mindset of managers and decision-makers has a crucial impact on how the opportunities offered by these new technologies can be capitalised. Our focus is on how and to what extent business performance management models need to be reviewed and reframed in this era of Big Data. We propose a model, called Balanced ScoreCard System Thinking, that may insure an integrative, highly dynamic and agile construction. This "top-down-bottom-up" approach assess the way in which every segment of the Balance Score Card is affected by Big Data and Business Analytics. These findings may enable business leaders to develop a more agile and forward-looking approach to performance management, which is only made possible through these new technologies of data analytics.
\end{abstract}

Keywords: Business reporting, Big Data, Business Analytics, Balanced Scorecard, System Thinking, Drivers

\section{Introduction}

Continuous improvement is needed to achieve excellence and there is a constant dynamic that should be accommodated within a modern organization. Nothing stays still, everything is in motion and up-dates and fresh actions are required at all business levels.

Information technologies continuously challenge the business landscape, offering new opportunities and forcing companies to adopt innovative approaches in order to perform in increasingly competitive markets. Business Intelligence, Big Data, Business Analytics and Artificial Intelligence transform the models companies use to define their strategy and to analyze their performance, both for management and integrated financial reporting scope.

Big Data and Business Analytics (BD\&BA) had a major impact in customer-facing industries and are rapidly penetrating all the business fields. Organizations are struggling to integrate a data-driven approach within their operations and business processes. The datadriven organizational culture became rapidly the new paradigm in the academic world and a standard to which all the businesses aspire to.

This paper investigates the challenges raised by the "datafication" of the business environment in the area of performance management. In our previous research, we 
investigated the managers' attitudes towards these changes and their expectations through a new business performance management model (Pugna et al., 2019). We found that, above all, managers value the opportunities for adopting a more proactive approach to performance management that are offered by the new data-driven model. Another important finding was that managers are willingly to integrate BD\&BA in their current Business Performance Information Systems, as an extension of Business Intelligence capabilities.

PICBE $\mid 697$

Our focus in this research is on how and to what extent business performance management models need to be reviewed and reframed in this era of Big Data. More specifically, we investigate how the current framework of Performance Management (PM) should change to accommodate the new insights provided by BD\&BA. We consider the Balanced ScoreCard (BSC) as being the benchmark framework for performance management, as it is the most used strategic management instrument, capable not only to assess the business as a hole but also to integrate future perspective (Nielson, 2015). BSC, as a model called the "Closed-Loop Management System", was developed in the latest decades as an integrated framework in which KPIs can be connected via statistical tools and models of analysis (Kaplan \& Norton 2015).

The reminder of this paper is divided into 4 sections. The first section provides an overview of the performance management concepts and practice as it has been addressed in the literature. The following section cover the research methodology. The results are presented and discussed in the third section. The last section includes some final remarks, implications of our findings, limitations of this study and future research actions.

\section{Literature review}

The concept of Balanced ScoreCard was introduced in 1992 by Robert Kaplan and David Norton, in order to provide a holistic picture of the business. The BSC concept was developed to overcome the limitations of the financial reporting system and its success was almost instant, being adopted by a large number of companies from different industries but also by non-for-profit organizations and government entities around the world.

The authors, Kaplan and Norton, are explaining the BCS' success based upon a mix of non-financial measurements, that links the measurement to strategy and provide a causeand-effect analysis, reflection of the changing nature of technology, as the shift from tangible assets to intangible ones, and knowledge-based strategies (Kaplan \& Norton, 2001).

Although initially considered a performance management component, very soon it became obvious that the BSC, as a strategy measurement instrument, is not only about the past but "creates focus for the future". BSC had evolved as an organization framework "for a new strategic management system" (Norton \& Kaplan 2001).

A recent white paper provide evidence that $70 \%$ of 1000 companies investigated by the magazine Fortune use balanced scorecards systems and other participants in the study were planning to implement BSC ("Resources/Articles-White-Papers " - Balanced Scorecard Institute).

The BCS is a system based on financial and non-financial measurements, relevant to the organization's strategy, used to mainly communicating to employees, customers and shareholders the business performances and its achievements, in line with its mission and vision. These objectives aim to align business activities to the vision and strategy of the entity, to improve communication and monitor the organization's performance linked to strategic 
goals ("Resources/Articles-White-Papers"- Balanced Scorecard Institute). Another advantage of the BSC is that it links the short-term objectives with long-term strategies, harmonizing the past and present with the future perspective.

Performance management had evolved since the launch of BCS. The major transformation was based on the shift from tangible assets management to intangible assets, "as a major source of competitive advantage" (Kaplan \& Norton 2001). Improvement of intangible assets focus within a business generates a direct impact into revenue growth and productivity and leads to increasing quality of employees' activities, higher customers satisfaction and, ultimately increasing customers loyalty (Heskett et al, 1994).

A 2016 McKinsey Study revealed that $90 \%$ of companies under scrutiny have redesign their performance management systems and perceived direct improvements, 83\% said that there was a enhance of the communication quality between employees and managers, $79 \%$ of executives considered performance management a high priority (Catalano, 2016). The following trends on performance management were depicted: a) agile development: "help teams respond to unpredictability through incremental, iterative work cadences and empirical feedback ", b) more frequent goal setting, meaning to aligned more frequently the actions with goals, quicker corrections during the on-going processes, increasing accountability c) becoming public and transparent, d) continuous feedback structure based upon the real-time feed-back, check-ins, immediate connections e) enable leaders to be coaches, with leaders inspiring and empower their teams (Catalano, 2016).

In 2000 Kaplan and Norton introduced a new framework to assess the value-creating strategies, called the "Strategy Map (SM)". This concept emphasizes the critical items within the BSC and their links with the business strategy. Using a SM, an organization creates value by connecting its strategy with the "cause-and-effect" relationship within the four BSC segments: financial, customer, processes, learning and growth (Kaplan \& Norton, 2001).

Figure 1 depicts examples of cause-and-effect actions in connection to the organization strategy implementation: 


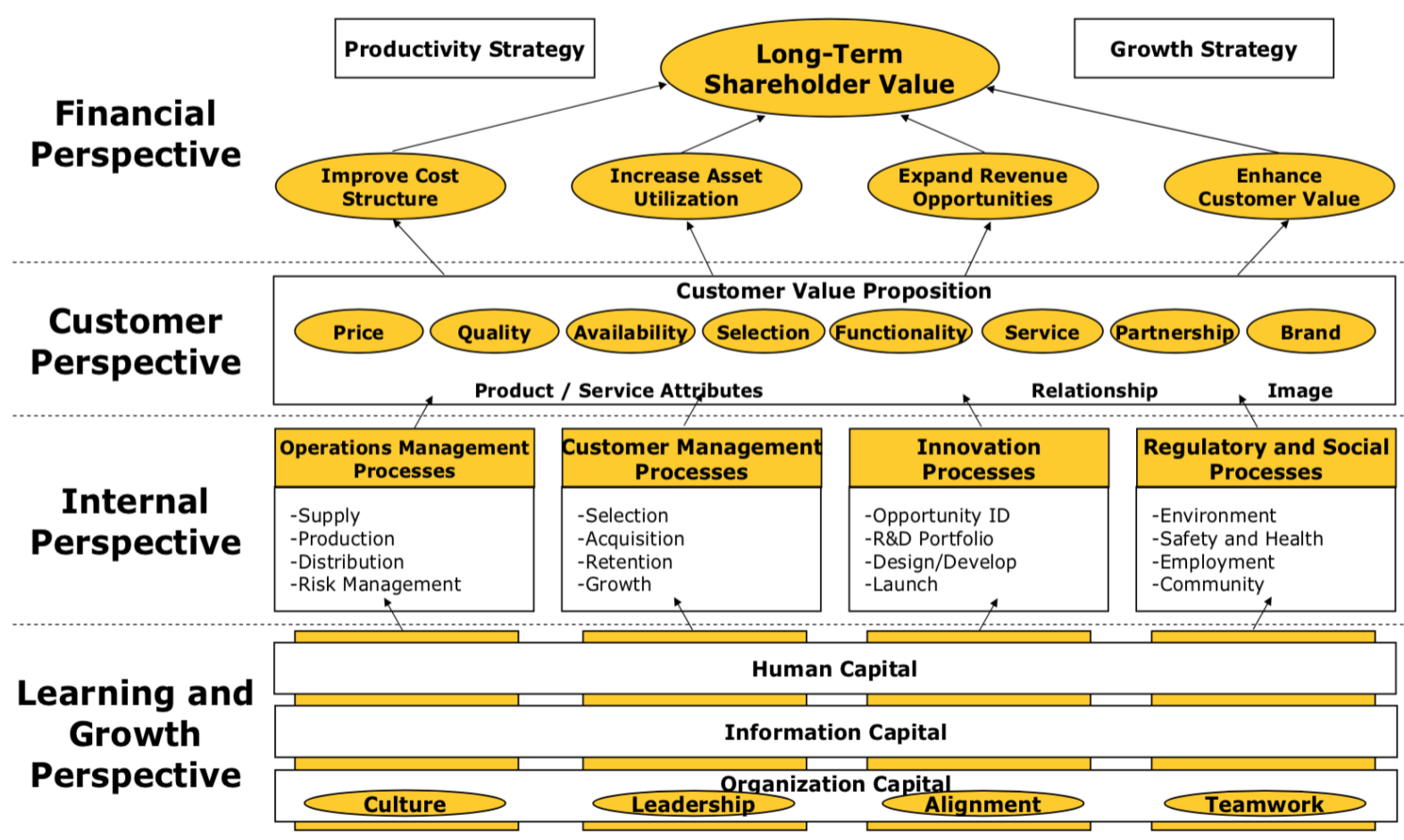

Figure 1. Strategy Map based on Kaplan and Norton model

Source: Kaplan \& Norton, 2001

The starting point of Kaplan and Norton's model is the strategic objective of increasing the shareholders' value, that is further-down embedded into growth strategy (revenue strategy) and productivity strategy; each strategy is then divided into interconnected actions of various sections: financial, customer, internal operations and learning and growing.

More recent studies aimed to embed philosophical concepts and "war games" principles into the system of performance management, providing answers to questions like: "How can Systems Thinking add value to the discussion of BSC as a strategic learning model by increasing scope and differentiations within the conceptual domain, and at the same time increasing the precision with respect to measurement and control within the methodology domain?" (Nielsen, 2015, pg. 2). An integrated, holistic approach on performance management, with permanent dynamics that reconfigures the entire system seems to be "the new trend in business" today.

\section{Methodology}

This paper aims to build up on "Strategy Map" (Kaplan \& Norton 2001), updated with the "BSC System Thinking" approach, introduced by Nielson in 2015, in which modeling items (e.g. delays, feed-back, employees satisfaction increase) and non-linearities occurring within the system generate dynamics that feed the cause-and-effect-loop. Strategic simulations are required (similarly in a war game), alongside with data optimization, provided by business intelligence and analytics. 
We see this paper as a continuation of our previous research, which focused on the impact of information technologies on the approaches organizations take to business performance management. We identified in a recent paper managers' expectations related to a performance management model that integrates BD\&BA (Pugna et al., 2019). The objective of the current paper is to further investigate how and to what extent BSC models need to be reviewed and reframed in a data-driven organisation.

PICBE $\mid 700$

Grounded on the "BSC System Thinking" concept, we are proposing a "fluid" integrated and interconnected framework, based on a "cause-effect-cause" loop, that enables every participant segment or activity to contribute to the success of the business. It is a "topdown-bottom-up" concept, that allows instant feed-back and correction both within and of the system. The starting point may be the mission and the vision of the organization, but it can be also an innovative incentive or peoples' empowerment actions, that might reshape the entire business paradigm. We are considering this theoretical development to be a two-steps approach: the first step is defining the integrating system, as an interconnected matrix and the second step is defining, for each segment, the specific objectives, measurement framework, targeted level and drivers.

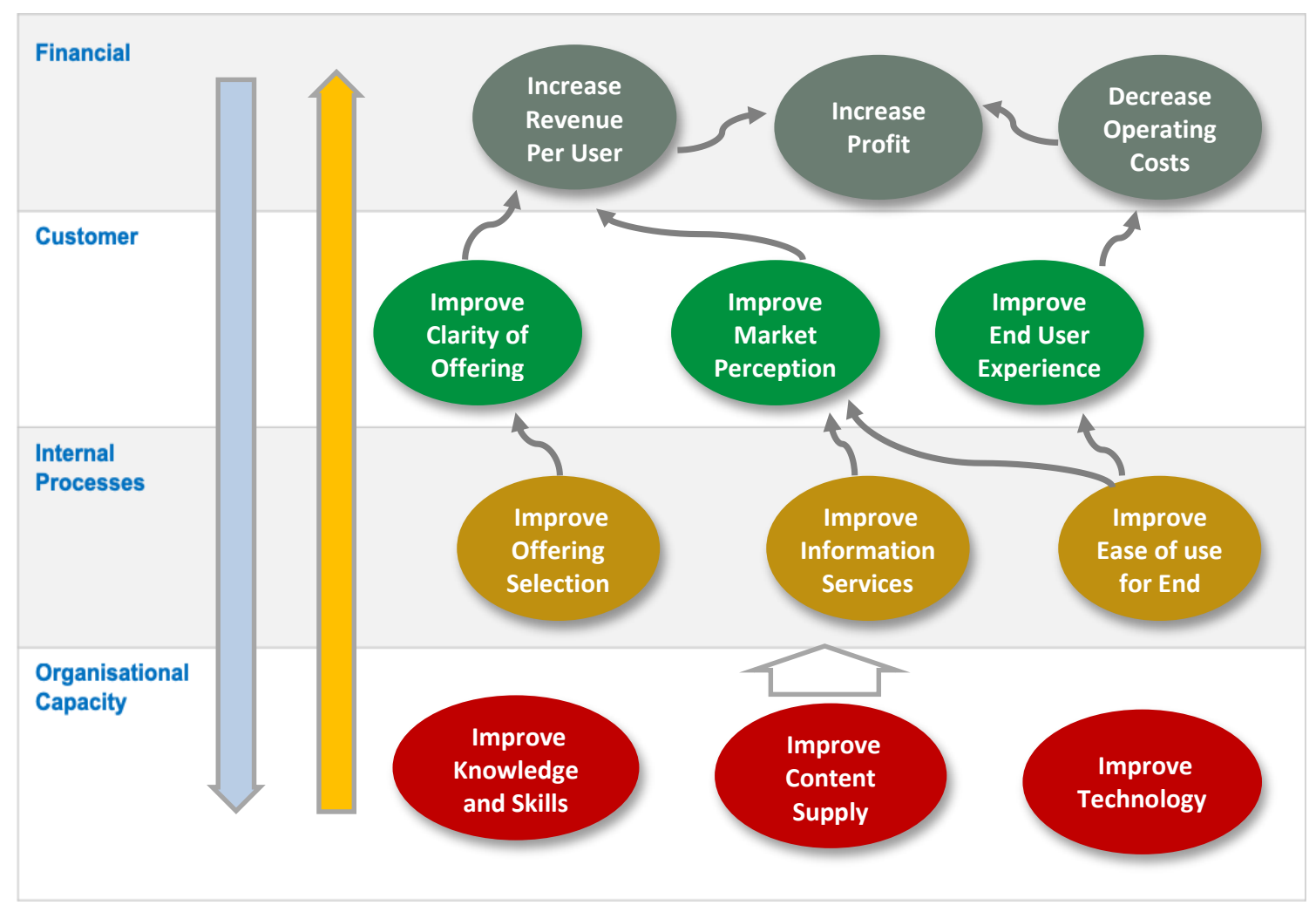

Figure 2. Strategy Map Framework

Source https://www.toolshero.com/strategy/balanced-scorecard/

The first step should emphasize a strategic approach of all dynamics within the system and loops generated by a "system thinking" premise. The second phase consists in designing a "interconnected-drivers-construction", that enables all material causes and effects to be imbedded into the scheme. 
The first phase of this "BSC System Thinking" framework is depicted in Figure 2, providing a brief description of the interconnected system. This first step aims to define the integrating system, the connections, feed-back loops and effects on different levels of the BSC. This phase may be considered as a "top-down" foundation, starting from the mission and the vision of the organization but only after assessing all input from the other levels (internal processes, customers' perceptions etc.) .

PICBE | 701

The second phase is developed as a break-through construction of the first phase, that provides the "BSC System Thinking" drivers on each segment, with more details about how to tailor and structure different areas and their inner and outer connections:

\section{Objectives Measures Targets Drivers}

\begin{tabular}{|c|c|c|c|c|}
\hline $\begin{array}{l}\text { Financial } \\
\text { "How attractive must we appear to our } \\
\text { shareholders and financial backers?" }\end{array}$ & $\begin{array}{ll}- & . . \\
- & . . \\
- & \text {.. }\end{array}$ & $\begin{array}{ll}\bullet & . . \\
\bullet & . . \\
- & . .\end{array}$ & $\begin{array}{ll}\bullet & . . \\
\bullet & . . \\
\bullet & . .\end{array}$ & $\begin{array}{ll}\bullet & . . \\
\bullet & . . \\
- & \text {.. }\end{array}$ \\
\hline $\begin{array}{l}\text { Customer } \\
\text { "How attractive should we appear to } \\
\text { our customers?" }\end{array}$ & $\begin{array}{ll} & . . \\
\bullet & . . \\
\bullet & . .\end{array}$ & $\begin{array}{ll} & . . \\
\bullet & . . \\
- & . .\end{array}$ & $\begin{array}{ll} & . . \\
\bullet & . . \\
\bullet & . .\end{array}$ & $\begin{array}{ll} & . . \\
\bullet & . . \\
- & . .\end{array}$ \\
\hline $\begin{array}{l}\text { Internal Business Processes } \\
\text { "What must we excel at to satisfy our } \\
\text { customers and shareholders/ financial } \\
\text { backers?" }\end{array}$ & $\begin{array}{ll}- & . . \\
\bullet & . . \\
- & . .\end{array}$ & $\begin{array}{ll}\bullet & . . \\
\bullet & . . \\
\bullet & . .\end{array}$ & $\begin{array}{ll}\bullet & . . \\
\bullet & . . \\
\bullet & \text {.. }\end{array}$ & $\begin{array}{ll}\bullet & . . \\
\bullet & . . \\
\bullet & . .\end{array}$ \\
\hline $\begin{array}{l}\text { Learning and growth } \\
\text { "How can we sustain our ability to } \\
\text { achieve our chosen strategy?" }\end{array}$ & $\begin{array}{ll} & . . \\
\bullet & . . \\
\bullet & . .\end{array}$ & $\begin{array}{ll} & . . \\
\bullet & . . \\
\bullet & . .\end{array}$ & $\begin{array}{ll} & . . \\
\bullet & . . \\
\bullet & . .\end{array}$ & $\begin{array}{ll} & . . \\
\bullet & . . \\
\bullet & . .\end{array}$ \\
\hline
\end{tabular}

Figure 3. "BSC System Thinking" drivers

Source https://www.toolshero.com/strategy/balanced-scorecard/

\section{Results and discussions}

The first phase of the "BSC System Thinking" framework may be considered a straightforward, clear and concise process, with unmaterial blurry areas. Based upon our previous research findings, it seems that one of the major limitations towards the data-drivenorganization, perceived by the managers, relates to the "lack of strategy". We did not look for more insights on what "strategy" means to different respondents but it can be assumed that it becomes more difficult to define who the organizations are "willing but also capable to be" and if this vision is coherent with the business environment, customers' perceptions and market development.

The main limitations highlighted by our respondents, identified as "lack of strategy and a lack of skills", can be than corelated to the expectations of the respondents on PM's improvements as, for example, "the ability (of PM) to simulate future scenarios on-time". This indicates that the entire construction of the classical business models should be revised and reshaped, into a flexible, more "self-adjusting frame", based on new skills and competences. 
The major challenge here is whether the new reshaped "BSC System Thinking" can rely mainly on the relevance and adequacy of "mission and vision" or it should also embed the dynamics generated by the new data-driven-environment and on-going technological progress. If we go more into a "System Thinking" paradigm to what extent organizations are prepared for this adventure? We consider this to be an open question for future research.

Once the first step solved, organizations can develop the second stage of the "BSC System Thinking", which consist of identifying, enforcing, assessing and adjusting the drivers. We consider "drivers" as being those actions or decisions that reshape the configuration of each segment of the BSC together with their dynamics. The idea of BSC drivers was derived from our previous research (Pugna et al., 2019) and they've emerged from the managers opinions on how the BSC should be reframed and adapted in a data-driven-organization. These drivers should be considered also a "loops' enhancers", based on their "cause-effect-cause" dynamic.

Managers' expectations related to the value added by BD\&BA in performance management are classified into two major categories: a normative category (Normative), that focuses on how BD\&BA should change PM systems and a descriptive category (Descriptive) that anticipates the expected impact (Pugna et al.,2019). The major outcomes are the followings:

Table 1. Normative category codes

\begin{tabular}{|c|l|l|}
\hline \multicolumn{2}{|c|}{ C-PM-Normative } & \multicolumn{1}{|c|}{ N } \\
\hline \multirow{2}{*}{$\begin{array}{c}\text { Integration } \\
\text { (I) }\end{array}$} & $\begin{array}{l}\text { Embedding prescriptive and predictive analytics } \\
\text { within the organization's approach to PM. (1) }\end{array}$ & NI-1 \\
\cline { 2 - 3 } & $\begin{array}{l}\text { Changing the approach to PM to align with the results } \\
\text { of BD\&BA. (2) }\end{array}$ & NI-2 \\
\hline \multirow{2}{*}{ Performance(P) } & $\begin{array}{l}\text { Improving predictability and awareness of levels and } \\
\text { changes in organizational performance. (3) }\end{array}$ & NP-3 \\
\cline { 2 - 3 } & $\begin{array}{l}\text { Improving the accuracy, relevance and consistency of } \\
\text { performance measures. (4) }\end{array}$ & NP-4 \\
\hline \multirow{2}{*}{ Development(D) } & $\begin{array}{l}\text { Utilizing the results of prescriptive and predictive } \\
\text { analytics in the area of PM for strategic organizational } \\
\text { development. (5) }\end{array}$ & ND-5 \\
\hline
\end{tabular}

Source: developed from Pugna et al. 2019

a) On normative category ( $\mathrm{NC}$ ) we identified some main themes: better integration, by embedding prescriptive and predictive analytics within the organization's approach to PM and changing the approach to PM to align with the results of BD\&BA; improved performance, by increasing the predictability and awareness of levels and changes in organizational performance and by enhancing the accuracy, relevance and consistency of performance measures; enabled development by utilizing the results of prescriptive and predictive analytics in the area of PM for strategic organizational development. (Table 1) 
b) On descriptive category (DC) respondents expect increasing efficiency and timeliness from the decision-making process, allowing data to directly drive decision making (or at least part of it) in order to increase agility and productivity. (Table 2)

Table 2. Descriptive category codes

\begin{tabular}{|c|l|l|}
\hline \multicolumn{2}{|c|}{ C-PM-Descriptive } & \\
\hline \multirow{2}{*}{ Efficiency(E) } & $\begin{array}{l}\text { Utilizing the results from the } \\
\text { approach to PM to better } \\
\text { inform decision making. (1) }\end{array}$ & DE-1 \\
\cline { 2 - 3 } & $\begin{array}{l}\text { Allowing data to directly drive } \\
\text { decision making (or at least } \\
\text { part of it). (2) }\end{array}$ & DE-2 \\
\hline \multirow{2}{*}{ Timeliness (T) } & $\begin{array}{l}\text { Allowing the approach to PM } \\
\text { to increase agility and } \\
\text { productivity. (3) }\end{array}$ & DT-3 \\
\hline
\end{tabular}

We propose the following framework, as a result of mapping the normative and descriptive categories into the SM system, for each particular segment:

a) In the mission and vision sector the normative driver ND-5 ("Utilizing the results of prescriptive and predictive analytics in the area of PM for strategic organizational development") should be considered and analyzed. This driver is fostering an ongoing, dynamic and up-dated business frame, capable to increase the strategic flexibility and agility of the organization. The side-effect costs and inners efforts that organizations should incure should also be assessed and included in further tests.

b) In the financial segment the normative drivers NI-1, NI-2, NP-3 are predominant, favoring a broad area for prescriptive and predictive analytics impact, on different financial performance items (NI-1), increasing compliance with BD \& BA (NI-2) and improving the predictability and awareness at different organizational levels (NI-3). In the same time another important driver may be the descriptive DE-1, which can be seen as a consequence of the application of the normative drivers but also as an independent one, fostering the efficiency of the decision-making process. This DE-1 driver is equally important to all four segments of the BSC System Thinking. Another important descriptive driver is DE -2, in the sense that the financial segment may shift into a result of the bottom-up dynamics of the PM in data-driven-organizations, being influenced by learning and growing, internal processes and customers perspective areas.

c) In the area of customers perspective, the normative drivers NI-1, NI-2, NP-3 are also predominant, emphasizing mainly the of BD\&BA effects while the descriptive driver DE-1 is adding value on increasing efficiency of the decision-making processes. 
Additionally, there is another normative driver, NP-4, that, in our opinion, plays a leading role, acting as an expected consequence of the actions of all other drivers.

d) Internal business process segment is focusing on normative drivers NI-1, NI-2, NP-3 and descriptive driver DE-1, closely matching the customer perspective objectives. There are two more descriptive drivers to be activated here: DE-2 and DT -3 . DE-2 allows the impact of data-driven-decisions to reconfigure the system and DT 3 , as a targeted scope, increase the overall agility of the processes. This area may the considered the most dynamic and turbulent in the "BSC System Thinking", BD\&BA having a direct impact on a continuous basis; both streams "top-down" and "bottomup" are increasing their speed and force in the internal business process area.

e) Learning and growing area is the most complex, as all drivers directly affect this segment: normative drivers NI-1, NI-2, NP-3, NP-4, ND-5 and descriptive drivers DE$1, \mathrm{DE}-2, \mathrm{DT}-3$. In this respect the prescriptive and predictive analytics impact should enable BD\&BA to improve the predictability and awareness at different organizational levels, and also the accuracy, relevance and consistency of performance measures. As a consequence, an improvement of the quality of the decision-making process is to be expected, based on the value-added by the datadriven processes. Therefore, the agility and dynamics of the organization should be enhanced. This is also a field of "time matrix", using the past and present experience to redefine the future.

The following table is providing a summary of the "BSC System Thinking" model:

Table 3. BSC System Thinking- drivers

\begin{tabular}{|c|c|c|c|c|}
\hline SEGMENTS & Objectives & Measures & Targets & Drivers \\
\hline $\begin{array}{l}\text { Mission } \\
\text { Vision }\end{array}$ & TBD & TBD & TBD & ND-5 \\
\hline Financial perspective & TBD & TBD & TBD & $\begin{array}{ll}- & \mathrm{NI}-1 \\
\text { - } & \mathrm{NI}-2 \\
\text { - } & \mathrm{NP}-3 \\
\text { - } & \mathrm{DE}-1 \\
\text { - } & \mathrm{DE}-2\end{array}$ \\
\hline Customer perception & TBD & TBD & TBD & $\begin{array}{ll}- & \mathrm{NI}-1 \\
\text { - } & \mathrm{NI}-2 \\
\text { - } & \mathrm{NP}-3 \\
\text { - } & \mathrm{NP}-4 \\
\mathrm{DE}-1\end{array}$ \\
\hline $\begin{array}{l}\text { Internal Business } \\
\text { Processes }\end{array}$ & TBD & TBD & TBD & $\begin{array}{ll}\text { - } & \text { NI-1 } \\
\text { - } & \text { NI-2 } \\
\text { - } & \text { NP-3 } \\
\text { - } & \text { DE-1 } \\
\text { - } & \text { DE-2 } \\
\text { - } & \text { DT-3 }\end{array}$ \\
\hline
\end{tabular}




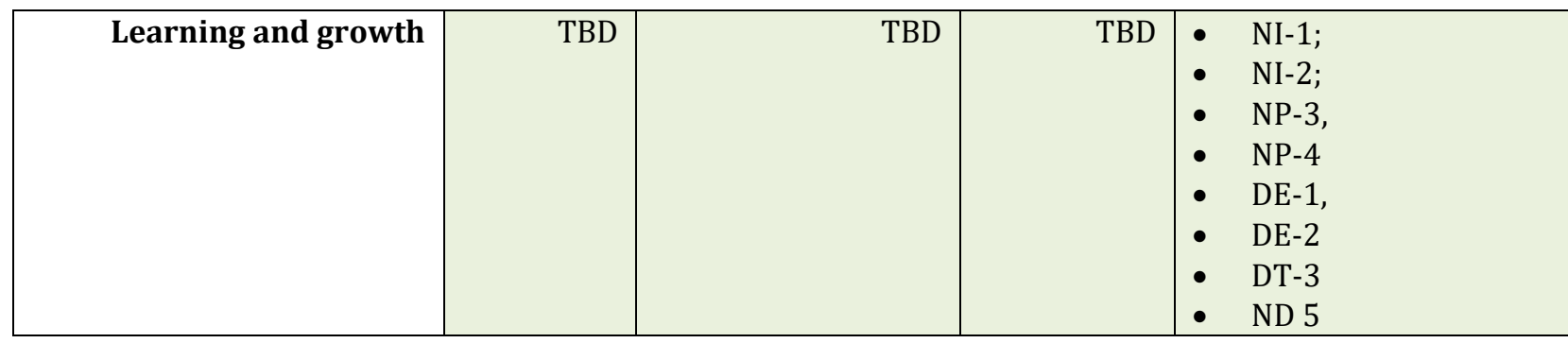

PICBE $\mid 705$

Source: Author's own research

In order to be validated this model requires a fine-tuning process, based on further testing in companies of different industries and various sizes.

\section{Conclusion}

This paper explores the possible challenges and changes of the BSC Framework, structure and inter-connections, in a data-driven-organization. We based our model on the Strategy Map proposed by Kaplan and Norton in 2000, configurated into a "System Thinking" paradigm, used by Nielson in a 2015 research project. Our model, called BSC System Thinking aims to insure an integrative, highly dynamic and agile construction that offers the possibility to assess the business in a "top-down-bottom-up" loop, every segment being affected, directly or indirectly by BD\&BA.

Based on the results of our previous research, we developed a two-steps approach in developing the proposed BSC System Thinking model. The first step is about assessing the on-going accuracy and adequacy of the organization's mission and vision and its flexibility in integrating the dynamics generated by the new data-driven-environment. In a second step we proposed a set of drivers, as actions or decisions that reshape the configuration of each segment of the BSC, either based upon data-driven-processes or man power or both. These drivers were built upon the classification of managers' views regarding the expected impact BD\&BA on performance management model. We configured two major drivers, Normative and Descriptive, each being divided into different subcategories, reflecting managers' assessments (integration, performance, development, efficiency and timeliness). Each segment of the BSC was analyzed and reassessed, based upon specific drivers and their potential effect. This fluid structure ("top-down-bottom-up") would, probably, generate multiple effects not only in the configuration of BSC but also in the way strategies are addressed and implemented.

The value added of this article is the specific contribution to the design and utility of BSC, in the context of the new (Big) Data analytics that force managers to considerably reshape their approach of performance management. In this context the proposed BSC System Thinking model represents the main result of our research. However, as the main limitation of our study, is this is an untested and unvalidated our model, in a specific business setup.

As a future research objective, we envisage to implement the BSC System Thinking model in different industries in order to explore its capabilities and limitations, alongside with changing behavioral patterns within organization as a result of this challenge. We shall also intend to test and assess future side-effects of this model's implementation and their holistic impact into the business framework. 


\section{References}

Kaplan, R. S., Norton, D. P. (1996). The Balanced Scorecard- Translating Strategy into Action, Harvard Business School Press, Boston, Mass, USA,

Kaplan, R. S., Norton, D. P. (2001). Transforming the Balanced Scorecard from Performance measurement to Strategic Management,: Part I", Accounting Horizons, 15 (1), pag. 87-104, USA,

Kaplan, R. S., Norton, D. P. (2001). Transforming the Balanced Scorecard from Performance measurement to Strategic Management,: Part II”, Accounting Horizons,, pag. 8147 160, USA

Kaplan, R. S., Norton, D. P. (2007). "Using the balanced score card as a strategic management system," Harvard Business Review, vol. 85, no.7-8, 150-194.

Catalano, R. (2016). Transforming Performance Management: 2018 Trends, McKinsey \& Company. Retrieved from https://www.hrpa.ca/Documents/AnnualConference/2018-Speaker-Notes-Day2/Catalano,\%20Rob\%20\%20Transforming\%20Performance\%20Management\%20-\%20Rob.pdf

Heskett, J., Jones, T., Loveman, G., Sasser, E. and Schesinger, L. (1994) Putting the service profit chain to work, Harvard Business Review, 164-174

("Resources/Articles-White-Papers " - Balanced Scorecard Institute)

Nielson, S., Nileson, E.H. (2015) The Balanced Scorecard and the Strategic Learning Process: A System Dynamics Modeling Approach, Hindawi Publishing Corporation Advances in Decision Sciences Volume, Article ID 213758, pag 1-20, Retrieved from http://dx.doi.org/10.1155/2015/213758

Pugna, I., Dutescu, A., Stanila G.O. (2019), Corporate Attitudes towards Big Data and Its Impact on Performance Management: A Qualitative Study. Sustainability, Volume 11, Issue 3, 684, Retrieved from http://www.mdpi.com/2071-1050/11/3/684/htm

Balanced Scorecard Resources, website- "Balanced Scorecard Institute" https://balancedscorecard.org/Resources/The-Nine-Steps-to-Success. Toolshero, Balance Score Card, 2019, available at; https://www.toolshero.com/strategy/balanced-scorecard/ 